\title{
FORMAÇÃO CONTINUADA DE PROFESSORES DE EDUCAÇÃO INFANTIL EM EDUCAÇÃO AMBIENTAL VIVENCIAL: A EXPLORAÇÃO DOS PÁTIOS DAS ESCOLAS
}

Bruna Medina Finger Arnholdt ${ }^{1}$ Jane M. Mazzarino²

Resumo: O objetivo é investigar um processo de formação continuada em Educação Ambiental vivencial com professores de Educação Infantil, no qual utilizou-se o Método do Aprendizado Sequencial como forma de explorar as possibilidades dos pátios das escolas. Partindo de uma abordagem qualitativa, de caráter descritivo, adotou-se a perspectiva intervencionista (pesquisa-ação), baseada nas pesquisas bibliográfica, documental e de campo. Fez-se uso da observação, registros (em diários de bordo e fotografias) e entrevistas individuais e em grupo. Os resultados referem-se a dois momentos do processo: o planejamento e a primeira etapa da formação continuada e as implicações desta na prática das professoras que participaram da segunda etapa do programa.

Palavras-chaves: Formação Continuada; Professores de Educação Infantil; Educação Ambiental Vivencial; Pátio Escolar; Método do Aprendizado Sequencial.

Abstract: The objective is to investigate a process of continuing education in experiential Environmental Education with teachers of Early Childhood Education, in which the Sequential Learning Method was used as a way to explore the possibilities of the schoolyard. Starting from a qualitative, descriptive approach, the interventionist perspective (action research) was adopted, based on bibliographic, documentary and field research. Observation, records (in logbooks and photographs), and individual and group interviews were used. The results refer to two moments in the process: planning and the first stage of continuing education and its implications for the practice of teachers who participated in the second stage of the program.

Keywords: Continuing Education; Early Childhood Education Teachers; Experiential Environmental Education; School Yard; Sequential Learning Method. 


\section{Introdução}

Os docentes da Educação Infantil têm sido chamados a dar conta de processos de ensino e de aprendizagem que rompem com as instâncias tradicionais, contemplando dimensões sensíveis na construção do conhecimento de mundo das crianças. Nesta perspectiva, a interação com os ambientes naturais mostra-se relevante.

Todas as escolas possuem algum tipo de ambiente externo que possibilita a realização de práticas de Educação Ambiental. No entanto, percebe-se a necessidade de programas de formação continuada que orientem os professores de Educação Infantil sobre os modos de explorar o contato com a natureza em sua prática. Uma das possibilidades existentes para este tipo de proposta é o Método do Aprendizado Sequencial.

Através de uma pesquisa com intervenção na realidade escolar, professores da Educação Infantil da rede municipal de Lajeado/RS foram convidados para participarem de um programa de formação continuada. Dentre estes, alguns aceitaram pôr em prática as vivências desenvolvidas na formação, aplicando às suas turmas experiências com o Método do Aprendizado Sequencial.

O problema que norteou a pesquisa foi compreender de que maneira um programa de formação continuada para professores de Educação Infantil com ênfase na exploração dos pátios das escolas pode afetar as práticas de Educação Ambiental. Nesse sentido, o objetivo do artigo é investigar um processo de formação continuada em Educação Ambiental vivencial com professores de Educação Infantil, explorando os pátios das escolas por meio do Método do Aprendizado Sequencial. A formação foi deflagrada pelo Grupo de Pesquisa Comunicação, Educação Ambiental e Intervenções (Ceami/CNPq) da Universidade do Vale do Taquari - Univates.

Entende-se que os programas de formação continuada possibilitam a prática da investigação pelos professores sobre sua escola, motivando-os a ampliar seus conhecimentos a partir da reflexão da sua realidade e das necessidades de seus alunos. Ao longo do processo de investigação-açãoparticipativa buscou-se valorizar o "ser criança" de cada docente, incentivandoos a se colocarem na posição dos alunos ao planejarem e dinamizarem propostas. Por meio de propostas permeadas pela sensibilidade e prática amorosa consigo, com o outro e com a natureza, buscou-se possibilitar aos professores participantes uma reflexão sensível de suas práticas e uma reaproximação com a natureza.

A pesquisa teve uma abordagem qualitativa, de caráter descritivo. A pesquisa-ação esteve baseada nas pesquisas bibliográfica, documental e de campo, quando fez-se uso de observação, de registros em diários de bordo e fotográfico e de entrevistas individuais e em grupo.

Os capítulos teóricos, que antecedem o aprofundamento metodológico e as análises, tratam da relação da sociedade com a natureza na 
contemporaneidade, da formação continuada de professores da Educação Infantil em Educação Ambiental e da proposta do Método do Aprendizado Sequencial como uma possibilidade sensível.

O referencial teórico deste artigo está organizado em três partes. Inicialmente abordaram-se questões que contextualizam a escola diante do distanciamento das pessoas para com a natureza. Após, organizaram-se concepções sobre a formação continuada de professores em Educação Ambiental. Por fim, abordaram-se especificamente as questões voltadas ao método escolhido para a realização das práticas com as crianças.

\section{A escola diante do distanciamento da natureza}

A sociedade foi constituída, ao longo dos tempos, pautando seu desenvolvimento nos pressupostos do capitalismo, do consumismo e das influências midiático-tecnológicas. Neste contexto, o ser humano construiu e reforçou uma ética antropocentrista e uma racionalidade antinatural que destituiu sua relação de parceria com a natureza. $\mathrm{O}$ ambiente natural passou a ser visto e entendido como um bem explorável para fins econômicos e financeiros (LEFF, 2012; GRÜN, 2012; GONÇALVES, 1989).

Atualmente há um número expressivo de habitantes nos centros urbanos que residem em moradias com pouco ou nenhum pátio externo. Assim, cada vez o contato cotidiano com a natureza é menor. Essa é a realidade de muitas crianças desde a sua primeira infância, o que acarreta um desenvolvimento geral alienado ao mundo natural (DUARTE JR, 1991).

Tendo sua rotina pautada na organização das suas próprias famílias, é comum as crianças frequentarem a Educação Infantil em turno integral. Portanto, passam mais tempo na escola do que com suas famílias. Desse modo, o contato com a natureza passa a fazer parte das demandas, cada vez mais abrangentes, destinadas aos professores (TARDIF; LESSARD, 2008).

Partindo desta constatação, entende-se que a formação dos professores precisa dar conta destas novas questões, voltando-se para a reflexão das nuances da realidade na qual atuam (RINALDI, 2012). Neste sentido, é necessário que os processos educativos levem em conta os conhecimentos prévios dos alunos em uma aproximação sensível com a natureza.

\section{A formação continuada de professores de Educação Infantil em Educação Ambiental}

A educação vem reorganizando-se continuamente acompanhando as mudanças sociais, o que requer que os professores se desprendam das amarras dos currículos tradicionais, que reproduzem os pressupostos do senso comum (ANTUNES, 2002; TRISTÃO; JACOBI, 2010; DUARTE JR, 1991). 
Imbernón (2010), ao analisar o histórico do desenvolvimento dos programas de formação continuada de professores nos últimos cinquenta anos, identifica que: passou-se da formulação e multiplicação de manuais e apostilas (nas quais o professor detinha o conhecimento e o aluno somente o recebia) para a necessidade emergente de discussão sobre o currículo (em uma prática colaborativa e democrática entre professor e aluno). Desse modo, mostra-se, cada vez mais evidente que, para dar sentido a sua práxis, o professor precisa estar atento à realidade dos seus alunos (BARCELOS, 2015; MOYLES, 2010; RINALDI, 2012; SATO, 2002).

A prática docente contemporânea vem tendo de abranger uma dinâmica complexa que exige o domínio de conhecimentos científicos, didáticos e culturais, o que evidencia a relevância de manter a qualidade da formação dos professores (TARDIF, LESSARD; 2008; BRAULT, 1994). No Brasil, a garantia de formação continuada está presente em lei (BRASIL, 1996; BRASIL, 1997). Porém, analisando a realidade atual, há de se reconhecer que boa parte dos docentes não tem acesso ou encontra-se desmotivada para participar destes processos (MADALÓZ; ORMEZZAN, 2013; ZAKREVSKI, 2003).

Especificamente em relação à Educação Ambiental, os processos de formação para os professores estão previstos no Programa Nacional de Educação Ambiental (PRONEA) (BRASIL, 2014) e no Programa Nacional de Formação de Educadores (as) Ambientais (PROFEA) (BRASIL, 2006). O PRONEA prevê linhas de ação e estratégias para a formação de professores, a fim de oportunizar o acesso a programas específicos e à produção de material científico e pedagógico sobre a temática.

No PROFEA, a Educação Ambiental é entendida como o meio para se desenvolver a relação com a natureza. Pautando-se nos princípios da Política Nacional de Educação Ambiental (PNEA) (BRASIL, 1999) e do PRONEA, o PROFEA visa:

[...] qualificar as políticas públicas federais de Educação Ambiental para que exijam menos intervenções diretas e ofereçam mais apoio supletivo às reflexões e ações autogeridas regionalmente, no sentido de desenvolver uma dinâmica nacional contínua e sustentável de processos de formação de educadoras (es) ambientais a partir de diferentes contextos (BRASIL, 2006, p. 5).

Uma sociedade sustentável com melhor qualidade de vida aos cidadãos é construída por meio da interlocução entre as políticas públicas e as necessidades reais da sociedade civil. O amparo legal, no entanto, não garante a prática e efetivação dos programas de formação continuada em Educação Ambiental, já que se percebe uma defasagem e uma incoerência entre estes documentos e a prática docente (TOZONI-REIS, et al., 2013; BONOTTO, 2005; GOUVÊA, 2006). 
No caso da Educação Ambiental na Educação Infantil, constata-se que a maioria dos profissionais não possui formação inicial com ênfase na temática. Assim, tendem a se sentirem inseguros, o que torna comum encontrar nas escolas um único professor interessado nos temas ambientais, sem que haja o engajamento do grupo (TRISTÃO; JACOBI, 2010; AMORIM; CASTANHO, 2008; MADALÓZ; ORMEZZAN, 2013).

De acordo com as Diretrizes Curriculares Nacionais da Educação Infantil (DCNEI), as práticas educativas nesta etapa do ensino são norteadas pelo brincar e pelas interações com o meio, promovendo, entre outros aspectos, o cuidado e a preservação. No documento, afirma-se que experiências que estimulem o conhecimento de si e do mundo ampliam a confiança e a participação das crianças nas atividades individuais e coletivas. A articulação de vivências estéticas com o ambiente e com pessoas de convívio incentivam a "curiosidade, a exploração, o encantamento, o questionamento, a indagação e o conhecimento das crianças em relação ao mundo físico e social, ao tempo e à natureza" (BRASIL, 2010, p. 26).

O Referencial Curricular Nacional para Educação Infantil (RCNEI) explicita que, à medida em que realizam experimentações com e no meio em que convivem, as crianças descobrem o mundo, constroem significados $e$ estabelecem as noções de cuidado consigo, com os outros e com a natureza (BRASIL, 1998).

De modo similar, na Base Nacional Comum Curricular (BNCC) está previsto que o trabalho na Educação Infantil tem de contemplar as dimensões ética e estética por meio da exploração do corpo, do outro e do meio. Nesta fase, o aprendizado ocorre na dinamização de propostas lúdicas que permitem a participação democrática e a livre expressão. Cabe ressaltar que não há uma abordagem específica sobre a Educação Ambiental, mas esta se insere em vários aspectos abordados no decorrer do documento (BRASIL, 2017).

Para que a prática de Educação Ambiental na Educação Infantil contemple os pressupostos previstos em lei faz-se necessário engajar os professores. Há de se considerar que a bagagem histórico-cultural de cada profissional incide na sua prática e precisa ser levada em conta, já que a sua formação tem início na infância e desenvolve-se durante a vida (OSTETTO, 2008; BARCELOS, 2015; CARVALHO, 2008; MADALÓZ; ORMEZZAN, 2013, BONOTTO, 2005).

Além disso, ao se abordar a configuração dos programas de formação continuada, é preciso considerar alguns pontos específicos. Primeiramente, incentivar o caráter investigativo, reflexivo e crítico de cada professor (SMITH; CRAFT, 2010). Também, entender que o foco da prática educativa está no aluno, não subestimando suas capacidades cognitivas. Da mesma forma, partir da realidade em que o professor atua, priorizar e valorizar o que se tem e o que vem sendo feito (MOYLES, 2010; BARCELOS, 2005). 
Independentemente de sua formação inicial, o professor de Educação Infantil pode realizar atividades de Educação Ambiental, entrelaçando suas competências pessoais com o conhecimento profissional (SCHÖN, 2000; TRISTÃO, 2013). Há um leque de possibilidades sensíveis e, entre eles, a exploração dos pátios das escolas através de uma abordagem vivencial, mostra-se um caminho potente.

\section{A proposta para a exploração dos pátios escolares: o Método do Aprendizado Sequencial}

As interações que as crianças estabelecem nos e com os espaços são importantes para o seu desenvolvimento. Portanto, é fundamental incluir as atividades ao ar livre no fazer pedagógico da Educação Infantil.

As crianças, na faixa etária da Educação Infantil, mostram-se extremamente sensíveis às propostas interativas e de exploração (ZINI, 2013), - que converge com as práticas educativas vivenciais. Aproximando a experiência do cognitivo, estas propostas desconstroem os pressupostos tradicionais, preconizando que as sensações vêm antes da consciência (RODRIGUES, 2015). Além disso, ao se envolver o corpo e a sensibilidade em uma aprendizagem plena, interacionista e socializadora, deixam-se marcas na história da criança (LARROSA, 2000; MENDONÇA, 2016).

Neste sentido, o pátio das escolas se apresenta como ambiente potente para aprendizagens mediadas pelos professores, podendo desenvolver nas crianças o espírito de segurança e a autoconfiança, quando as aproxima da natureza (MOYLES, 2010). Pensar a Educação Ambiental por meio de práticas do Método do Aprendizado Sequencial, organizado por Joseph Cornell, possibilita essa reaproximação com encantamento.

Cornell organiza as atividades em quatro estágios específicos que precisam ser seguidos ordenadamente para que o objetivo proposto seja alcançado de forma efetiva. O primeiro estágio, denominado como despertar $o$ entusiasmo dá início ao processo de participação: gera-se o interesse em aprender divertindo-se e estimula-se a receptividade à proposta. No segundo estágio, denominado como concentrar a atenção, o mediador estimula o grupo a focar na proposta, possibilitando ao participante sentir-se parte da natureza por meio de atividades que tranquilizam a mente. $O$ terceiro estágio, dirigir a experiência, é o momento de sintonizar os participantes à natureza, experimentando o ambiente em sua totalidade e potencialidade por meio das descobertas individuais. O último estágio, depois do cumprimento de todos os outros, é para compartilhar a inspiração: os participantes trocam impressões sobre como foi a experiência por meio de interpretações que fortalecem as experiências pessoais (CORNELL, 2008a; 2008b;1997).

É necessário que o mediador se aproxime das crianças, respeitando-as e incentivando a reverência pela natureza. Para que isso se efetive, o autor postulou cinco regras fundamentais: ensinar menos e compartilhar mais;

revista brasileira educação ambiental 
mostrar-se receptivo; concentrar a atenção dos participantes; incentivar para que sintam primeiro e falem depois; manter um clima de alegria durante a experiência.

Espera-se que o mediador esteja envolvido e motivado com a proposta, atento para que cada participante tenha uma experiência de "apreciação profunda da Natureza, aceitando-o a partir do ponto em que se encontra e ajudando-o a dar o próximo passo em direção a uma percepção sensível e mais ampla" (CORNELL, 2008b, p. 166). Assim, respeitam-se as reações e as percepções de cada envolvido, que são muito particulares e individuais.

Devido às especificidades do método em questão, entende-se que os professores, enquanto mediadores das interações com a natureza, necessitam de formação específica para a sua apropriação, o que motivou a pesquisaação.

\section{Método}

O estudo é qualitativo, tem caráter descritivo e explora a perspectiva intervencionista. Foi organizado a partir das pesquisas bibliográfica, documental e de campo, quando se fez uso da observação, de registros em diário de bordo e por meio de fotografias, além de entrevistas individuais e em grupo. A pesquisa de campo foi acompanhada pela pesquisa-ação que:

Pressupõe uma participação planejada dos pesquisados na situação problemática a ser investigada. $O$ processo de pesquisa recorre a uma metodologia sistemática, no sentido de transformar as realidades observadas, a partir da sua compreensão, conhecimento e compromisso para a ação dos elementos envolvidos na pesquisa (THIOLENT, 1992, p. 34).

Pelo fato de ser necessário que os participantes se relacionassem de maneira pertinente ao assunto, a escolha da amostra seguiu os critérios de seleção não probabilística por tipicidade. Como estratégia para atrair os professores, gratuitamente, ofereceu-se um programa de formação continuada em Educação Ambiental vivencial para professores de Educação Infantil do município de Lajeado/RS. A formação foi ofertada pelo grupo de pesquisa Ceami e previu cinco encontros presenciais. Vinte e três professoras participaram. Destas, cinco aceitaram dar continuidade ao processo de Educação Ambiental com suas turmas, experienciando o Método do Aprendizado Sequencial nos pátios de suas escolas (segunda etapa). Estas profissionais tiveram um aprofundamento teórico sobre o método e suas práticas foram acompanhadas pela primeira autora.

No início e no final do processo, estas professoras foram entrevistadas tanto individualmente quanto em grupo. As entrevistas caracterizaram-se pela 
profundidade, "processo que consiste em dirigir a conversação de forma a colher informações relevantes" (ANGROSINO, 2009, p. 61). As entrevistas seguiram um guia semiestruturado de questões abertas que abordaram os seguintes temas: Educação Ambiental na Educação Infantil (percepções, conceitos e práticas); a exploração e o entendimento dos pátios das escolas enquanto ambientes de aprendizagem; as vivências com a natureza na Educação Infantil; o Método o Aprendizado Sequencial como prática de Educação Ambiental vivencial; os programas de formação continuada em Educação Ambiental para professores de Educação Infantil; reflexões; expectativas; dúvidas; inquietações. Todas as entrevistas foram transcritas para facilitar as análises.

As participantes também foram convidadas a escrever suas reflexões em diários de bordo e suas experiências com as crianças foram registradas em fotografias. A técnica da observação possibilitou registrar as intervenções das professoras nas suas escolas para, posteriormente, cruzar os dados com elementos da fundamentação teórica e da pesquisa bibliográfica. Esta triangulação fez emergir análises sobre dois elementos: o planejamento e a primeira etapa da formação continuada e as implicações desta na prática das professoras que participaram da segunda etapa do programa.

\section{Análises e discussões}

Primeiramente relata-se o planejamento do programa de formação continuada como um todo, refletindo sobre as questões que emergiram durante a primeira etapa. Em seguida, abordam-se as implicações do programa na prática das professoras ao longo da segunda etapa da pesquisa de campo.

\section{a) O planejamento e o programa de formação continuada - $1^{a}$ etapa}

Aprofundando os estudos sobre o referencial bibliográfico e em documentos legais, verificou-se a existência de previsões pouco cumpridas de formação continuada em Educação Ambiental para professores de Educação Infantil (TRISTÃO; JACOBI, 2010; BRASIL, 1996; BRASIL, 1997; BRASIL, 2014; BRASIL, 2006).

A partir desta evidência e estando o grupo de pesquisa Ceami orientado para investigações sobre Educação Ambiental vivencial, optou-se por buscar compreender de que maneira um programa de formação continuada para professores de Educação Infantil com ênfase na exploração dos pátios das escolas por meio do Método do Aprendizado Sequencial pode vir a multiplicar práticas de Educação Ambiental. Deste modo, planejou-se o curso de formação continuada em cinco encontros presenciais na Univates (quatro noturnos e um diurno), que aconteceu no período de aproximadamente um mês.

Partiremos da análise do número de participantes no programa. $O$ município de Lajeado possui vinte e três Escolas Municipais de Educação 
Infantil e, aproximadamente, quinhentos e trinta profissionais atuam nesta etapa do ensino. O convite para participação no programa se estendeu a toda rede municipal.

Vinte e três professoras aderiram à proposta, representando $4,5 \%$ do total dos profissionais que atuam na Educação Infantil municipal. Das 30 vagas disponíveis, 7 não foram preenchidas e todos que entraram em contato com os organizadores participaram da pesquisa.

As professoras participantes atuavam em dez escolas municipais diferentes. Desse modo, a pesquisa abrangeu $43 \%$ das instituições, o que demonstra uma representatividade considerável de possíveis instituições multiplicadoras das práticas na rede escolar.

Até o final da pesquisa, a rede municipal não havia ofertado um programa de formação continuada nesta abordagem, mesmo estando garantido em lei. As participantes relataram que não há uma cobrança para a participação em programas de formação (exceto os que são organizados pelo próprio município).

A partir destas informações e considerando que o programa foi ofertado para uma demanda emergente, atraída pelo fato de ser gratuito, oferecer certificação de participação e partir do interesse específico e individual de cada profissional, o número de interessados mostrou-se pequeno em relação ao total de profissionais que atuam nesta etapa do ensino. Ou seja, teve-se uma boa representatividade de instituições para a propagação dos conhecimentos, porém, poucos profissionais interessados.

Inicialmente buscou-se compreender o contexto no qual as professoras atuavam, abordando aspectos de sua trajetória pessoal e profissional e considerou-se que sua prática é atravessada pelo entrelaçamento das instâncias cognitivas e sensíveis (TARDIF; LESSARD, 2008). Assim, dois dos cinco encontros foram para a exploração de experiências que envolvessem o corpo e explorassem os sentidos na prática pedagógica. Estes momentos de interação entre as próprias professoras consigo, com o grupo e com a natureza tiveram a intenção de fazê-las sentir o que possivelmente seus alunos sentiriam se colocados nestas situações.

O foco do programa esteve relacionado à construção de um processo educativo em que o aluno estivesse no centro das ações pedagógicas e o professor ciente das características individuas das crianças e da escola em que atua, elementos considerados essenciais para o ensino e a aprendizagem (BARCELOS, 2015; RINALDI, 2012; MOYLES, 2010). O Quadro 01 sintetiza o programa desenvolvido na primeira etapa. 
Quadro 1: Proposta de formação continuada desenvolvida na primeira etapa do programa de formação continuada.

\begin{tabular}{|c|c|}
\hline Encontro & Propostas \\
\hline 1e encontro & $\begin{array}{l}\text { - Apresentação formal: pesquisadora, orientadora e projeto de } \\
\text { pesquisa. } \\
\text { - Termos de consentimento e autorização de uso de imagem } \\
\text { (leitura no grande grupo, explicações e preenchimento). } \\
\text { - Participantes: roda de conversa para apresentação; responder } \\
\text { questionário sobre o tema do programa. } \\
\text { - Discussões sobre o questionário. } \\
\text { - Leitura para o próximo encontro: material sobre Educação } \\
\text { Ambiental (conceitos e concepções). }\end{array}$ \\
\hline 2o encontro & $\begin{array}{l}\text { - Discussão sobre a leitura prévia. } \\
\text { - Realização da dinâmica "Linha do Tempo", cruzando história da } \\
\text { Educação Ambiental com as histórias de vida das participantes. } \\
\text { - Pátios das escolas: roda de conversa e apresentação das fotos } \\
\text { dos pátios das escolas das participantes. } \\
\text { - Leitura para o próximo encontro: material sobre Educação } \\
\text { Ambiental na Educação Infantil - vivências na natureza e o Método } \\
\text { da Aprendizagem Sequencial na exploração dos pátios das } \\
\text { escolas. }\end{array}$ \\
\hline 3e encontro & Discussões no grande grupo sobre a leitura prévia. \\
\hline $4^{\circ}$ encontro & $\begin{array}{llllll}\text { Vivência noturna na natureza explorando o } & \text { Método do } \\
\text { Aprendizado Sequencial. } & & & & \\
\end{array}$ \\
\hline 5 e encontro & $\begin{array}{l}\text { - Vivência diurna na natureza explorando o Método do Aprendizado } \\
\text { Sequencial, com construção de fotolivros individuais sobre a } \\
\text { experiência. }\end{array}$ \\
\hline
\end{tabular}

Fonte: Anholdt (2018).

Como não há uma cobrança para a participação em programas de formação, observou-se que a mesma esteve vinculada, em parte, ao interesse na progressão na carreira. Além disso, a partir da conversa sobre o questionário aplicado no primeiro encontro, evidenciou-se que as expectativas sobre o programa estiveram associadas à busca por novos conhecimentos, especificamente sobre práticas de Educação Ambiental na Educação Infantil, desarticulando-se da visão do professor como reprodutor dos conteúdos impostos pelos currículos tradicionais (DUARTE JR, 1991; IMBERNÓN, 2010).

Percebeu-se que a falta de formação sobre a temática fazia com que as professoras se sentissem inseguras metodologicamente. Neste sentido, salientou-se a relevância das formações serem planejadas considerando a realidade dos professores e suas implicações na prática (BARCELOS, 2005).

A maioria das participantes era graduada em Pedagogia e relatou não ter tido nenhuma disciplina voltada para Educação Ambiental durante sua formação acadêmica inicial. Isso mostra-se preocupante na medida em que quando não se tem contato com a área de estudo, o profissional tende a afastar-se da mesma, aproximando-se da que teve alguma experiência ou possui afinidade. Essa constatação relaciona-se à evidência de trabalhos em Educação Ambiental sendo, geralmente, realizados por um único professor, 
sem o engajamento do grupo todo (TRISTÃO; JACOBI, 2010; AMORIM; CASTANHO, 2008).

Quando questionadas sobre suas experiências particulares com a natureza, a maioria descreveu situações relacionadas a memórias de infância, citando lugares, pessoas e momentos. Várias professoras se emocionaram e foi possível perceber um sentimento de saudade da criança interior. Percebeuse que muitas deram-se conta do quanto a natureza fora importante em suas vidas, as revigorava e fazia bem. Porém, ao longo de sua trajetória, acabaram distanciando-se da natureza, o que gera também um afastamento entre a razão e a emoção (DUARTE JR, 2010).

Sobre o entendimento em relação à Educação Ambiental, observou-se claramente a evidência de duas lógicas no grupo. Uma relacionada às concepções tradicionais voltadas à separação do lixo, datas comemorativas, preservação do ambiente, entre outros. E a outra, referente às práticas de contato com a natureza, corpo e mente, busca de harmonia, com questionamentos sobre o capitalismo e o consumismo, a necessidade de reeducação, conscientização, atos de amor e cuidado com a natureza.

Ao relacionar a inserção das professoras de cada grupo com sua formação pedagógica, evidenciou-se que os sentidos atrelados à Educação Ambiental eram influenciados pelas diretrizes do campo da educação. $O$ primeiro grupo advém de uma educação tradicional, na qual o professor detinha o conhecimento e o aluno o recebia sem questionar. Em relação a Educação Ambiental, na época em questão, as legislações nacionais estavam sendo elaboradas ou recém haviam sido aprovadas, não incidindo com influência no contexto escolar (BRASIL, 1999).

O segundo grupo frequentou a escola quando os aportes legais se aproximaram mais da realidade. Assim, construíram seus conhecimentos por meio de uma educação mais democrática, que considera o aluno como atuante no processo de aprendizagem (GRÜN, 2012; BRASIL, 1999; BRASIL, 2014; BRASIL, 2006).

Quanto às práticas de Educação Ambiental na Educação Infantil que consideravam realizar, as professoras expuseram o que já faziam nos pátios das suas escolas. Relataram momentos de caminhadas, contemplação, exploração dos sentidos, cuidado com o meio ambiente, estudos específicos sobre plantas e animais, entre outros. Porém, não caracterizaram suas propostas como práticas de Educação Ambiental, evidenciando-se a crença de que para trabalhar a temática fazia-se necessária formação e metodologia específicas (BARCELOS, 2005).

No segundo encontro, houve o entrelaçamento dos marcos da Educação Ambiental com momentos marcantes da vida das professoras, por meio da Dinâmica da Linha do Tempo. Cada uma identificou, em pedaços de papel, o ano de seu nascimento e o ano de um fato importante em suas vidas. Com a análise da Linha do Tempo refletiu-se que, mesmo a temática estando presente 
na sociedade há várias décadas, ainda não se efetivava nas práticas das escolas e da sociedade.

Também, veio à tona a percepção de como as histórias de vida se entrelaçam ao desenvolvimento da sociedade no espaço-tempo. Na medida em que as professoras relacionaram que no ano do nascimento delas ou de um fato importante em suas vidas acontecia um evento de Educação Ambiental, perceberam que a mesma vem se desenvolvendo sem a devida atenção pedagógico-social.

Quando foram projetadas as imagens dos pátios das escolas, ficou evidente que muitos prédios foram construídos na mesma época ou provêm de reformas de casas já existentes, sem a valorização da influência do espaço no processo de ensino e de aprendizagem (CAMPOS-DE-CARVALHO; SOUZA, 2008; BARBOSA, 2006; CEPPI; ZINI, 2013). Constatou-se que houve o respeito à previsão legal com o foco no estabelecimento de uma estrutura que atendesse à demanda por vagas na Educação Infantil.

Os pátios foram sendo estruturados no entorno dos prédios e seguem padrões semelhantes. Muitos apresentavam chão coberto por cimento bruto ou piso cerâmico e alguns ambientes com areia, grama ou brita. Quatro escolas tinham um espaço com gramado e/ou um ambiente arborizado, livre para a exploração. Todas as escolas possuíam locais com brinquedos fixos e parecidos: playground de plástico, ou estruturas de metal com escorregadores e balanços, gangorras, rodas de gira-gira, entre outros.

Além das semelhanças na estrutura dos prédios e na organização dos pátios, perceberam-se aproximações nas características das crianças atendidas. A maioria frequenta a Educação Infantil em turno integral, numa jornada diária de aproximadamente dez horas por dia. Mostram-se influenciadas por um contexto midiático-tecnológico, residem em moradias localizadas nos centros urbanos com pouco ou nenhum pátio externo, o que torna as relações cada vez mais distantes da natureza e impessoais. Passando a maior parte do tempo em que estão acordadas na escola, as professoras pontuaram sua responsabilidade em aproximar as crianças do ambiente natural.

O segundo encontro encerrou instigando as professoras a refletirem sobre as possibilidades existentes nos pátios de suas escolas. Neste momento, foi disponibilizado um material sobre a exploração destes ambientes por meio de práticas vivenciais. Este foi o tema da conversa do terceiro encontro, quando se relacionou a teoria à prática das professoras participantes. Várias relataram que nunca haviam realizado leituras sobre a Educação Ambiental na sua formação acadêmica.

As professoras não conheciam o método proposto por Cornell (1997), porém perceberam relações com sua prática. Algumas associaram as etapas propostas por Cornell com as atividades realizadas na Educação Infantil: 
necessidade de iniciar as propostas com um momento de concentração; partir para a prática; compartilhar com o grupo e voltar à calma.

Listaram propostas que desenvolvem e enfatizaram a importância de se considerar a dimensão estética, bem como as interações no processo educativo (BRASIL, 2010; MARIN e KASPER, 2009; MATURANA, 1998; MENDONÇA, 2016; SILVEIRA, 2009; CORNELL, 1997). O grupo percebeu que, para a realização das práticas de Educação Ambiental não se faz necessária a busca por métodos extravagantes, sendo suficiente valorizar criativamente os recursos disponíveis (BARCELOS, 2005).

Como estas relações foram estabelecidas depois que as professoras conheceram uma metodologia específica, evidenciou-se a necessidade de formações para a reflexão crítica da prática pedagógica desenvolvida na Educação Infantil. Constatou-se que o programa de formação continuada permitiu o desenvolvimento de um olhar crítico-reflexivo às participantes.

Nos dois últimos encontros, as professoras experienciaram as vivências com a natureza conforme o Método do Aprendizado Sequencial. Um ocorreu à noite e outro pela manhã. As participantes foram incentivadas a imaginar adaptações para a experiência com as crianças, relacionando a proposta com suas ações pedagógicas.

Nestes encontros, observou-se a entrega das participantes com momentos de silêncio profundo e a participação nas atividades. Ao compartilharem a experiência, a emoção aflorou nos relatos, com muitas professoras expressando forte motivação para levar seus alunos a desfrutarem das mesmas sensações.

Elas compreenderam que o Método se apresenta como um leque de possibilidades de intervenções nos pátios das suas escolas. Perceberam a necessidade de valorizar atividades simples como o andar descalço, respirar pausadamente, contemplar, entre outras experiências que eram comuns à infância das professoras. Relataram que, para muitas crianças, se tais propostas não forem realizadas na escola, talvez não ocorram durante sua infância.

A formação continuada deu início a um processo reflexivo da práxis educativa. As professoras conseguiram analisar criticamente tanto o ambiente em que atuam quanto as práticas que realizam, relacionando esta análise aos pressupostos metodológicos apresentados. Foram incentivadas a proporcionar a contemplação e a sensibilidade na aproximação se si e dos seus alunos com a natureza.

Além disso, o programa permitiu que as professoras se atualizassem sobre práticas e concepções de Educação Ambiental vivencial, explorando possibilidades da e na realidade em que atuam. Portanto, ofertou-se uma formação contextualizada que partiu das vivências diárias e particulares de cada profissional. 


\section{b) Implicações do programa de formação continuada na prática das professoras}

Cinco professoras se voluntariaram para participar da segunda etapa da formação. Estas, desde o início do programa, mostraram-se engajadas com a temática, expondo suas subjetividades, percepções e interpretações entrelaçadas aos aspectos pessoais e a própria prática docente. Esta etapa levou cinco meses e dividiu-se em cinco fases, conforme apresentado no Quadro 2.

Quadro 2: Proposta desenvolvida na segunda etapa do programa de formação continuada.

\begin{tabular}{ll}
\hline Parte & \multicolumn{1}{c}{ Propostas } \\
\hline Parte 1 & $\begin{array}{l}\text { - Pesquisadora visitou a escola de cada professora participante. } \\
\text { - Entrega de material para leitura aprofundada sobre o Método do } \\
\text { Aprendizado Sequencial. } \\
\text { - Proposta às professoras participantes: leitura do material e seleção } \\
\text { de três atividades para realizar com sua turma. }\end{array}$ \\
\hline Parte 2 & $\begin{array}{l}\text { - Reflexão entre pesquisadora e as professoras participantes: } \\
\text { atividades selecionadas, espaço e materiais a serem utilizadas, } \\
\text { procedimentos, encaminhamentos, etc. }\end{array}$ \\
\hline Parte 3 & $\begin{array}{l}\text { - Formação para as professoras participantes. } \\
\text { - Aplicação das propostas planejadas (para desenvolver com as } \\
\text { turmas) entre as professoras participantes. } \\
\text { - Troca de experiencias sobre os momentos planejados: } \\
\text { adaptações, discussões, repensar, reorganizar, etc. }\end{array}$ \\
\hline Parte 4 & $\begin{array}{l}\text { - Período em que cada professora participante realizou as práticas } \\
\text { com suas turmas. }\end{array}$ \\
\hline Parte 5 & - Momento de compartilhamento das experiências: pesquisadora e \\
professoras participantes.
\end{tabular}

Fonte: Arnholdt (2018).

Inicialmente, a pesquisadora visitou cada professora na escola em que atua, para caracterizar o ambiente escolar e aproximar-se mais de cada participante. Neste momento, as professoras receberam material específico sobre o Método do Aprendizado Sequencial, a fim de selecionarem três atividades para desenvolverem com sua turma. Em um segundo momento, a pesquisadora e as professoras conversaram sobre as atividades selecionadas, espaço e materiais necessários.

No encontro seguinte, as professoras aplicaram as propostas entre si e realizaram uma roda de conversa para troca de experiências e possíveis alterações em seus planejamentos (de acordo com as discussões que partiram do grupo). Passadas estas etapas, que levaram cerca de quatro semanas, iniciaram-se as práticas com as turmas.

As primeiras preocupações das professoras referiam-se às possibilidades de adaptações do Método do Aprendizado Sequencial. 
Consideraram as características de desenvolvimento e interesses das suas turmas, os pátios de suas escolas e a necessidade de condições climáticas confortáveis às crianças, demonstrando cuidado para com o público e o contexto das atividades. Além disso, analisaram criticamente o pátio das suas escolas, considerando-o como um elemento influente no processo de ensino e de aprendizagem (CEPPI; ZINI, 2013).

A preocupação constante com o planejamento esteve relacionada, ainda, com a responsabilidade na construção das memórias das crianças. As professoras queriam que as mesmas sentissem o quanto o contato com a natureza faz bem para a vida delas. Portanto, as atividades teriam que alcançar este objetivo. Esta intenção revela que o planejamento das professoras vai além do período das aulas, sendo permeado pelas suas subjetividades, formação e experiências individuais, bem como características das crianças e do contexto como um todo.

Todas as professoras realizaram o que se propuseram no pátio de suas escolas, sendo que após terem trocado ideias entre si, algumas professoras repensaram seus planejamentos iniciais e fizeram alterações. Por exemplo, duas professoras diminuíram a duração das atividades, pois perceberam que as mesmas estavam longas e poderiam dispersar o grupo. Outras duas repensaram seu planejamento pelo fato de uma parte do pátio da sua escola ter sido isolada depois de uma forte chuva, que derrubou árvores.

Apropriando-se da flexibilização e da adaptação das propostas do Método do Aprendizado Sequencial, as atividades organizadas pelas professoras respeitaram as características das crianças. Algumas preocuparam-se com a segurança durante os deslocamentos, umas com o diálogo e outras em engajar as crianças nas propostas. Assim, percebeu-se o constante foco no aluno, o que fora abordado no programa de formação e condiz com os documentos norteadores já referidos (BRASIL, 1998; BRASIL, 2014; BRASIL, 2006).

Além disso, as particularidades relacionadas ao contexto de atuação de cada professora e a sua história de vida afetou a abordagem que cada uma deu para a mesma metodologia. Portanto, as atividades e o manejo com a turma estão relacionados com as subjetividades de cada profissional (SMITH; CRAFT, 2010).

As particularidades emergiram também em como as escolas receberam as propostas. Duas professoras viram suas ações se multiplicarem pelas suas instituições, envolvendo a comunidade como um todo (BRASIL, 1998; BRASIL, 2014; BRASIL, 2006). Nestas escolas ocorreram mudanças nos pátios, com a criação de uma horta e um jardim interativo, nos quais as crianças auxiliam no processo de cuidado.

Outra participante relatou ter realizado as propostas de forma isolada ao projeto da escola, sem o envolvimento ou interesse do grupo, o que gerou frustração. Essa situação reforça o apontamento feito por Tristão e Jacobi 
(2010), quando ressaltam que o trabalho em Educação Ambiental nas escolas é, muitas vezes, realizado por um único professor. Porém, com a proposta finalizada, a equipe da escola buscou mais informações com a participante e foi organizado um projeto relacionado à temática para todo o grupo escolar.

As professoras foram convidadas a registrar as percepções sobre a formação continuada e suas práticas. No quadro 03 estão descritas as observações das professoras participantes.

Quadro 3: Observações das professoras participantes sobre a implicação do programa de formação continuada em sua prática.

\begin{tabular}{|c|c|}
\hline Professora & Relato \\
\hline \multirow[t]{2}{*}{$\begin{array}{lr}\text { Professora } 01 & \text { e } 02 \\
\text { (trabalhavam em } \\
\text { dupla com a } \\
\text { mesma turma, } \\
\text { representando uma } \\
\text { escola } \\
\text { intervenção) }\end{array}$} & $\begin{array}{l}\text { Para mim o curso foi sensacional! Primeiramente por ter me feito } \\
\text { repensar e reviver momentos inesquecíveis da minha vida em se } \\
\text { tratando de Vivências com a Natureza. A maneira como o tema "nos } \\
\text { abordou" foi maravilhoso. Quanta emoção nos momentos em que } \\
\text { paramos tudo para observar, sentir e analisar a natureza de uma } \\
\text { maneira diferente daquela do cotidiano. }\end{array}$ \\
\hline & $\begin{array}{l}\text { Para mim marcaram muito as vivências com cada criança, os olhares } \\
\text { curiosos e as explorações. O que ficou na prática, a partir da formação, } \\
\text { foi um estímulo muito maior para (observar) os detalhes, ao cuidado e } \\
\text { atenção com tudo que a natureza nos proporciona. }\end{array}$ \\
\hline Professora 03 & $\begin{array}{l}\text { Após a formação, procurei mais referências sobre práticas relacionadas } \\
\text { ao meio ambiente. As leituras, reflexões e dinâmicas, realizadas na } \\
\text { formação, me ajudaram a perceber melhor a potencialidade do pátio } \\
\text { escolar, experimentando novas maneiras de utilizá-lo. }\end{array}$ \\
\hline Professora 04 & $\begin{array}{l}\text { Como eu fiz graduação em biologia, eu já tinha um olhar voltado ao } \\
\text { meio ambiente e à Educação Ambiental. Mas, com a formação e, } \\
\text { depois, com a prática com as crianças, eu pude perceber e obter um } \\
\text { olhar diferente de como eu conseguia trabalhar isso, porque o meu } \\
\text { olhar de bióloga era de que a prática só é possível com maiores, que é } \\
\text { meio que impossível de fazer com menores. E como a minha área de } \\
\text { atuação é com menores, com essa formação e, depois, a prática com } \\
\text { eles, eu pude perceber que dá sim pra fazer um trabalho diferente, } \\
\text { inovador e desafiante tanto pra mim quanto para as crianças e que isso } \\
\text { traz resultados muito positivos. }\end{array}$ \\
\hline Professora 05 & $\begin{array}{l}\text { Contribuiu muito para meu trabalho diário, ampliou o conhecimento das } \\
\text { crianças em relação aos fatos e acontecimentos da realidade social, } \\
\text { sobre os elementos e fenômenos naturais. }\end{array}$ \\
\hline Professora 06 & $\begin{array}{l}\text { A formação me fez muito feliz e contribuiu me motivando mais a } \\
\text { trabalhar essas questões, como o contato e a troca com a natureza, } \\
\text { fazer com que os pequeninos, desde cedo, valorizem e troquem } \\
\text { energia. }\end{array}$ \\
\hline
\end{tabular}

Fonte: Arnholdt (2018).

A experiência de formação e multiplicação das práticas vivenciadas em Educação Ambiental na Educação Infantil afetou as professoras de modo a provocá-las a repensarem sua relação com a natureza, deixar-se "abordar" por métodos que exploram a sensibilidade, o observar e o sentir. De aprendentes passaram a mediadoras de um olhar mais sensível na interação com 
elementos possíveis de serem explorados nos pátios escolares, mesmo que apresentem limitações.

Através das propostas desenvolvidas no programa de formação, as professoras experienciaram outros olhares, conhecimentos e outras formas de ser professora. Percebeu-se que a participação e as reflexões desenvolvidas, as motivaram em sua prática docente.

\section{Considerações Finais}

A pesquisa evidenciou a relevância dos programas de formação continuada partirem da reflexão sobre o contexto de atuação dos professores para aprimorar o seu saber-fazer pedagógico.

Aproximar-se das demandas das professoras e oferecer uma formação que explora as sensações do corpo, possibilitou o reencontro de cada uma consigo mesma e com a natureza. Isso se refletiu na relação pedagógica com as crianças, especialmente quando perceberam que talvez sejam as mediadoras mais importantes deste contato natural primordial e cada vez mais esquecido, mesmo em pequenas cidades.

O engajamento de cada uma que participou da segunda etapa de formação rompeu com a possível postura de acomodação, com o medo do novo e do desafio. Além disso, evidenciou-se a vontade de mudar e buscar estratégias para ir além das práticas tradicionais, que ainda marcam fortemente as rotinas escolares.

A pesquisa teve como foco trabalhar a formação de professores para que eles experienciassem as práticas de Educação Ambiental vivencial junto às crianças. Deste modo pensamos em uma pesquisa-ação que afetasse um maior número de escolas do que se tivéssemos optado por uma pesquisa que tivesse como grupo as crianças. Portanto, os resultados não se referem a como as crianças foram afetadas no processo, o que deixa em aberto possíveis problematizações para próximas pesquisas. Os resultados oferecem pistas sobre como as professoras surpreenderam-se ao reencontrarem-se com sua criança interior e com o que é possível criar nos pátios das suas escolas com recursos simples.

Deste modo, ao final do processo, nos encontramos com professoras motivadas por terem desconstruído estereótipos, acessando formas potentes e sensíveis de ser professoras. O programa de formação continuada implicou no desenvolvimento emocional e profissional das participantes. Cada professora pode inserir mudanças nas suas práticas a partir do conhecimento adquirido.

Mesmo que o foco da intencionalidade pedagógica seja o aluno, a formação em si precisa abraçar as demandas da criança interna do professor. $\mathrm{E}$ isto requer uma práxis educativa permeada pelo amor e pelo cuidado com o outro e com a natureza, de modo a contribuir para um mundo mais afetuoso e sensível. 


\section{Agradecimentos}

Ao Conselho Nacional de Desenvolvimento Científico e Tecnológico (CNPq), pelo apoio financeiro à pesquisa; à Universidade do Vale do Taquari Univates.

\section{Referências}

AMORIM, V.M.; CASTANHO, M.E. Por uma educação estética na formação universitária de docentes. Revista Educação \& Sociedade, Campinas, v. 29, n. 105, set./dez. 2008.

ANGROSINO, M. Etnografia e observação participante. Porto Alegre: ARTMED, 2009.

ANTUNES, C. Novas maneiras de ensinar, novas formas de aprender. Porto Alegre: Artmed, 2002.

ARNHOLDT, B.M.F. Educação Ambiental na Educação Infantil: as vivências com a natureza no pátio da escola. 2018. Dissertação (Mestrado em Ambiente e Desenvolvimento) - Programa de Pós-Graduação Ambiente e Desenvolvimento, Universidade do Vale do Taquari.

BARBOSA, M.C.S. Por amor e por força: rotinas na Educação Infantil. Porto Alegre: ARTMED, 2006.

BARCELOS, V.H.L. Educação Ambiental, Infância e Imaginação - uma contribuição à formação de professores(as). Quaestio - Revista de Estudos em Educação, v. 6, n.1, 2009.

BONOTTO, D.M.B. Formação docente em Educação Ambiental utilizando técnicas projetivas. Paidéia, Ribeirão Preto, v. 15, n. 32, set./dez. 2005.

BRASIL. Lei № 9.394 de 20 de dezembro de 1996. Disponível em: $<$ http://www.planalto.gov.br/ccivil 03/leis/L9394.htm>. Acesso em: 17 mar. 2016.

BRASIL. Lei no 9795 de 27 abril de 1999. Disponível em: $<$ http://www.planalto.gov.br/ccivil 03/leis/L9795.htm>. Acesso em: 11 ago. 2016.

BRASIL. Ministério da Educação e Cultura. Base Nacional Comum. Disponível em: <http://basenacionalcomum.mec.gov.br/>. Acesso em: 01 ago. 2017.

BRASIL. Ministério do Meio Ambiente e da Educação. Programa Nacional de Educação Ambiental - PRONEA. Brasília, 2014.

BRASIL. Ministério da Educação. Secretaria de Educação Básica. Diretrizes Curriculares Nacionais para a Educação Infantil. Brasília: MEC/SEB, 2010. Disponível em: <http://portal.mec.gov.br/index.php?option=com docman\&view= download\&alias=9769-diretrizescurriculares-2012\&category slug=janeiro-2012pdf\&ltemid=30192>. Acesso em: 17 mar. 2016. 
BRASIL. Órgão Gestor da Política Nacional de Educação Ambiental. Programa Nacional de Formação de Educadoras (es) ambientais - PROFEA. Brasília, 2006.

BRASIL. Referencial curricular nacional para a Educação Infantil. Brasília: MEC/SEF, 1998. 3.v. Disponível em: <http://portal.mec.gov.br/seb/arquivos/pdf/ rcnei vol1.pdf>. Acesso em: 11 ago. 2016.

BRASIL. Secretaria de Educação Fundamental. Parâmetros Curriculares Nacionais: Apresentação dos Temas Transversais, Ética. Brasília: MEC/SEF, 1997. 146p. Disponível em: <http://portal.mec.gov.br/seb/arquivos/ pdf/livro01.pdf>. Acesso em: 11 ago. 2016.

BRAULT, M. A formação do professor para a Educação Básica: perspectivas. Brasília: MEC/UNESCO, 1994.

CAMPOS, M.C.; SOUZA, T.N. de. Psicologia Ambiental, Psicologia do Desenvolvimento e Educação Infantil: integração possível? Paidéia, Ribeirão Preto, v. 18, n. 39, 2008.

CARVALHO, I.C.M. Educação Ambiental: a formação do sujeito ecológico. São Paulo: Cortez, 2008.

CEPPI, G.; ZINI, M. Crianças, espaços, relações: como projetar ambientes para a Educação Infantil. Porto Alegre: Penso, 2013.

CORNELL, J. A alegria de aprender com a natureza: atividades na natureza para todas as idades. São Paulo: Companhia Melhoramentos, 1997.

CORNELL, J. Vivências com a natureza. $3^{a}$ ed. São Paulo: Aquariana, 2008a.

CORNELL, J. Vivências com a Natureza 2: novas atividades para pais e educadores. São Paulo: Aquariana, 2008b.

DUARTE, J.F. O sentido dos sentidos: a educação (do) sensível. 5a ed. Curitiba: Criar Edições, 2010.

DUARTE, J.F. Por que arte - educação?. 6⿳a ed. São Paulo: Papirus, 1991.

GASKELL, G. Entrevistas individuais e grupais. In: BAUER, M.W. GASKELL, G. (Orgs.) Pesquisa qualitativa com texto, imagem e som: um manual prático. Petrópolis: Vozes, 2002.

GONÇALVES, C.W.P.G. Os (des) caminhos do meio ambiente. São Paulo: Contexto, 1989.

GOUVÊA, G.R.R. Rumos da formação de professores para a Educação Ambiental. Educar em Revista, Curitiba, n. 27, jan./jun. 2006.

GRÜN, M. Ética e Educação Ambiental: a conexão necessária. 14ª ed. São Paulo: Papirus, 2012.

IMBERNÓN, F. Formação continuada de professores. Porto Alegre: ARTMED, 2010. 
LARROSA, J. Pedagogia Profana: danças, piruetas e mascaradas. Belo Horizonte: Autêntica, 2000.

LEFF, E. Aventuras da epistemologia ambiental: da articulação das ciências ao diálogo dos saberes. São Paulo: Cortez, 2012.

MADALÓZ, R.J.; ORMEZZAN, G.R. Formação pessoal e docente: o acesso pela via corporal. Revista de Ciências Humanas, v. 14, n. 23, dez. 2013.

MARIN, A.A.; KASPER, K.M. A natureza e o lugar habitado como âmbitos da experiência estética: novos entendimentos da relação ser humano - ambiente. Educação em Revista, Belo Horizonte, v. 25, n. 2, ago. 2009.

MATURANA, $H$. Emoções e linguagem na educação e na política. Belo Horizonte: UFMG, 1998.

MENDONÇA, R. Educação Ambiental Vivencial. In: FERRARO-JUNIOR, L.A. (Org.) Encontros e caminhos: formação de educadoras(es) ambientais e coletivos educadores. Brasília: MMA, 2007. Disponível em: $<$ http://www.institutoroma.org.br/artigos/educacao ambiental vivencial.pdf 2016>. Acesso em: 12 mar. 2016.

MOYLES, J. Fundamentos da Educação Infantil: enfrentando o desafio. Porto Alegre: ARTMED, 2010.

OSTETTO, L.E. Educação Infantil: saberes e fazeres da formação de professores. Campinas: Papirus, 2008.

RINALDI, C. Diálogos com Reggio Emilia: escutar, investigar e aprender. São Paulo: Paz e Terra, 2012.

RODRIGUES, C. O vagabonding como estratégia pedagógica para a "desconstrução fenomenológica" em programas experienciais de Educação Ambiental. Educação em Revista, Belo Horizonte, v. 31, n. 1, jan./mar. 2015. Disponível em: <http://www.scielo.br/scielo.php?pid=S010246982015000100303\&script=sci abstract\&tlng=pt>. Acesso em: 12 ago. 2016.

SATO, M. Relações multifacetadas entre as disciplinas. In: Congresso Brasileiro de Qualidade na Educação: formação de professores. Relações multifacetadas entre as disciplinas. Brasília, MEC, SEF, 2002. v. 3.

SCHÖN, D.A. Educando o Profissional Reflexivo: um novo design para o ensino e a aprendizagem. Porto Alegre: Artes Médicas Sul, 2000.

SILVA, I.S. da. 2010. Educação Ambiental, Intercultura e Antropofagia cultural brasileira - contribuições para a formação de professores (as). Dissertação (Mestrado em Educação) - Curso de Mestrado em Educação, Programa de Pós-Graduação em Educação, Universidade Federal de Santa. Disponível em: $<$ http://www.ambiente.sp.gov.br/wp-content/uploads/cea/Antropofagia.pdf>.

Acesso em: 05 ago. 2015. 
SILVEIRA, E. A arte do encontro: a educação estética ambiental atuando com o teatro do oprimido. Educação em Revista, Belo Horizonte, v. 25, n. 3, dez. 2009

SMITH, A.P.; CRAFT, A. 0 desenvolvimento da prática reflexiva na Educação Infantil. Porto Alegre: Artmed, 2010.

TARDIF, M.; LESSARD, C. O ofício de professor: história, perspectivas e desafios internacionais. Petrópolis: Vozes, 2008.

THIOLENT, M. Metodologia da pesquisa-ação. São Paulo: Cortez, 1992.

TOZONI-REIS, M.F.C. et al. A inserção da Educação Ambiental na Educação Básica: que fontes de informação os professores utilizam para sua formação? Revista Ciência \& Educação, Bauru, v. 19, n. 2, 2013.

TRISTÃO, M.; JACOBI, P.R. Educação Ambiental e os movimentos de um campo de pesquisa. São Paulo: Anablume, 2010.

TRISTÃO, M. Uma abordagem filosófica da pesquisa em Educação Ambiental. Revista Brasileira de Educação, Rio de Janeiro, v. 18, n. 55, out./dez. 2013.

VERGARA, S.C. Projetos e relatórios de pesquisa em administração. $5^{\underline{a}}$ ed. São Paulo: Atlas, 2004.

VERGARA, S.C. Projetos e relatórios de pesquisa em administração. 12 ed. São Paulo: Atlas, 2010.

ZAKREVSKI, S. B. Cenários da trajetória da Educação Ambiental. In: ZAKREVSKI, S. B. (Org.). A Educação Ambiental na escola: abordagens conceituais. Erechim: Edifapes, 2003. 